\title{
IMPLIED MORTGAGE REFINANCING THRESHOLDS
}

\author{
Paul Bennett, Richard Peach, and Stavros Peristiani \\ Research and Market Analysis Group \\ Federal Reserve Bank of New York \\ Second draft, June 12
}

Send correspondence to: Stavros Peristiani, Research and Market Analysis Group, Main 3 East, Federal Reserve Bank of New York, New York, NY 10045, U.S.A.

Phone: 212-720-7829; E-mail: steve.peristiani@ny.frb.org.

*The authors thank Dibora Amanuel for valuable research assistance. Any views expressed in this paper are those of the author. They should not be interpreted as reflecting the views of the Federal Reserve Bank of New York or the Federal Reserve System, and their staff. 


\begin{abstract}
$A B S T R A C T$
The optimal prepayment model asserts that rational homeowners would refinance if they can reduce the current value of their liabilities by an amount greater than the refinancing threshold, defined as the cost of carrying the transaction plus the time value of the embedded call option. To compute the notional value of the refinancing threshold, researchers have traditionally relied on a discrete option-pricing model. Using a unique loan level dataset that links homeowner attributes with property and loan characteristics, this study proposes an alternative approach of estimating the implied value of the refinancing threshold. This empirical method enables us to measure the minimum interest rate differential needed to justify refinancing conditional on the borrower's creditworthiness, remaining maturity, and other observable characteristics.
\end{abstract}




\title{
IMPLIED MORTGAGE REFINANCING THRESHOLDS
}

\author{
Paul Bennett, Richard Peach, and Stavros Peristiani
}

June 12, 1998

\section{INTRODUCTION}

When options are bundled with debt instruments - as in call options on bonds or prepayment options on mortgages - the decision to exercise is often bundled with other financing decisions. Calling existing debt typically involves issuing new debt as well, and so the cost-benefit calculus will encompass several related steps rather than an isolated transaction. Accordingly, the value of a mortgage option and the likelihood of its exercise may depend not only on option-theoretic considerations (e.g., strike and market prices, expected price volatility, discount rate, and time-to-expiration) but also on factors specific to the individual debtor's availability and cost of replacement funding, including transaction costs. One way of quantifying the importance of these factors is by their impact on the required threshold values of gains to be reaped by refinancing. At one extreme, with zero transactions costs and no change in the terms and availability of replacement funding, a pure options-theoretic model of exercise may be appropriate, with only time-value considerations limiting the exercise of in-the-money refinancing options. Toward the opposite extreme, credit downgrade, collateral deterioration, or high transactions cost could raise the required threshold gain from refinancing, impeding such activity.

This paper develops a way to compute refinancing thresholds for fixed-rate home mortgage loans, based on actual homeowner refinancing behavior and conditional on individual characteristics and market conditions. Our approach is to estimate a model of conditional refinancing probabilities, and then, consistent with option-theoretic considerations, to locate thresholds based on where the impact of market volatility on refinancing probabilities is optimized. 
One type of approach to understanding refinancing thresholds is to simulate optimizing behavior under various assumptions. At the simplest level, some financial advisors may compute refinancing costs and develop rules of thumb about how many basis points a homeowner should save to justify refinancing. At the other extreme of complexity, some studies have used carefully detailed binomial techniques to compute refinancing rules, which for example may be sensitive to factors such as market volatility conditions (e.g., see Follain, Scott, and Yang 1992; Chen and Ling 1989; Yang and Maris 1996).

Such rules are "normative" in that they provide thresholds that would be optimal given a set of debtor objectives and constraints. A drawback is that such a methodology may miss unobserved transactions costs or other idiosyncratic factors affecting refinancing decisions a particularly important consideration for home mortgages. Thus, while highly instructive, normative simulation results must be viewed with a degree of caution by investors, bankers, loan servicers, and others concerned with predicting how refinancings or prepayments will actually develop.

As a "positive" approach, our study estimates thresholds implied by actual observed household behavior. Our technique is to take advantage of the expectation that a change in mortgage rate volatility will have its greatest impact on refinancing decisions of individuals whose costs and benefits of refinancing are nearly balanced - e.g., who are "at their thresholds". These vega thresholds are computed from a sufficiently well-specified statistical model that the size of the thresholds can be made conditional on individual characteristics and mortgage market conditions.

In the next section, we formalize the theory of the option vega. We illustrate that fundamentally the vega of any option (including that of a mortgage option) attains a maximum when it is near the money. In section 3 , we demonstrate how this property of the mortgage option can be applied in a statistical context. In particular, we illustrate that 
there is a direct relationship between the vega of the mortgage option and the probability of refinancing. In section 4, we use this methodology to estimate the refinancing threshold needed to justify refinancing for different values of volatility, maturity, and household creditworthiness.

\section{THE VEGA THRESHOLD}

The right to prepay a mortgage is equivalent to a call option that allows a homeowner to refinance all future obligations of the mortgage loan at the outstanding balance of the loan. Like any other call option, the mortgage option depends on several factors: the contract interest rate, which determines the intrinsic value of the loan; the volatility of the risk-free interest rate process; the remaining maturity of the loan, etc. An important problem in the mortgage refinance literature is finding the effective interest rate differential between contract rates that can justify refinancing. This interest rate differential is essentially equivalent to the point at which the mortgage option goes in the money.

For most typical option contracts (e.g., calls or puts on stock or bond assets), moneyness is easily established because the strike price and current asset price are transparent. Mortgages, however, are more complex options that are influenced by other esoteric factors. An alternative way to infer the moneyness of the option is to look at how the value of option responds to changes in the underlying factors. In particular, in this study we consider the sensitivity of the value of the option to changes in volatility - the vega of the option. From hedging analysis, we know that shifts in market volatility have their strongest effect on option values when options are near the money (for more details, see Hull 1993). In the appendix, we show analytically that this property holds for a variety of European option contracts. More specifically, we demonstrate that the vega of a European call option reaches a maximum at

$$
S^{*}=X e^{-r(T-t)} e^{0.5(T-t) \sigma^{2}}
$$


Here, $S^{*}$ represents the vega threshold (that is, the asset price at which the vega attains a maximum $),(X)$ denotes the strike price of the option, $(r)$ is the risk-free rate, and $(T-t)$ is the time-to-expiration. For the seller of the option, this value represents essentially the future value of the proceeds, adjusted for the risk of uncertainty.

\subsection{The Vega of the Mortgage Option}

The option-pricing theory of a fixed-rate mortgage has been extensively studied in the mortgage finance literature (see Archer, Ling, and McGill 1996; Follain, Scott and Yang 1992. For a graphical illustration of the mortgage option see also Quigley and Van Order 1990). Let $P\left(T, t, r_{0}\right)$ represent the face value of a callable mortgage loan at period (t) with an original contract rate $\left(r_{0}\right)$ and maturity $(\mathrm{T})$ months. Similarly, $P\left(T, t, r_{m}\right)$ denotes the value of the same loan but discounted at the prevailing market rate $\left(r_{m}\right)$. The debtor maximizing his or her net worth would refinance when the following inequality holds:

$$
P\left(T, t, r_{0}\right)-P\left(T, t, r_{m}\right)>T C,
$$

where (TC) stands for the total cost of the refinancing transaction. However, we also need to recognize the value of the embedded option. Because a mortgage is callable, its value can be expressed as the sum of a noncallable amortizing bond, or annuity, minus the value of the mortgage call, that is, $P(T, t, r)=P^{N C}(T, t, r)-V(T, t, \sigma, r)$. Transactions costs conceptually include all economic costs associated with carrying out the refinancing, both the repayment of outstanding debt and issuance of new debt. In the case of a home mortgage, there may be time and money costs associated with paying back the loan, particularly if there were prepayment fees or legal expenses. Most of the total transaction cost, however, is typically associated with securing the replacement financing. This will include points and fees, legal expenses, transaction taxes, plus the "shoe leather" and time of the debtor. To account for this broad range of refinancing costs and the embedded value 
of the call option, we modify the right hand side of equation (2):

$$
P^{N C}\left(T, t, r_{0}\right)-P^{N C}\left(T, t, r_{m}\right)>T C(p, c, \ell)+\nu(T, t, \sigma),
$$

where the variable (p) represents points and fees, (c) defines the credit quality of the borrower, and $(\ell)$ the loan-to-value ratio. The term $\nu(T, t, \sigma)$ equals the net value of the call option, i.e., $V\left(T, t, \sigma, r_{0}\right)-V\left(T, t, \sigma, r_{m}\right)$. The expression on the left side of inequality, defined by the difference of the noncallable present values evaluated at the two alternative rates, represents the "intrinsic" benefit of refinancing. The intrinsic gains are available to homeowners if the option is exercised immediately. The right hand side of the inequality represents the refinancing threshold faced by a homeowner. This threshold consists of the transaction costs and the net value of the call option.

In comparison to European Black-Scholes model, the mortgage option is a more complex American-type contingent claim. Most American options (especially those with timevarying volatility or path-dependent parameters) do not have an easy closed-form solution. In the absence of a simple analytical solution for the mortgage option, one can employ the binomial tree model to price the mortgage option (Cox, Ross and Rubinstein 1979; Rendleman and Bartter 1980; Hall 1985). In the binomial world, the vega can be approximated numerically by computing values of the mortgage option on trees with volatilities $\sigma$ and $\sigma+\Delta \sigma$ (where $\Delta \sigma$ is small). Mathematically,

$$
\operatorname{vega}=\frac{V_{\sigma+\Delta \sigma}-V_{\sigma}}{\Delta \sigma}
$$

Figure 1 presents the vega of the mortgage option for three different mortgage contracts (2-year, 5-year, and 10-year). Besides maturity, the remaining characteristics of the three mortgage contracts are identical. ${ }^{1}$ The vega threshold, plotted on the x-axis, represents the difference present value of the mortgage and the book value of the original

\footnotetext{
1 We computed the value of the mortgage call by adapting the Rendleman and Bartter
} 
balance (measured as a percent). The relationship between the mortgage option vega and the intrinsic value is concave and is fundamentally similar to that of the European stock option discussed in the appendix. Note that the vega of the 10-year mortgage option attains a maximum at a higher threshold, reflecting the fact that value of the mortgage call increases with maturity.

As seen from equation (3), an important element in mortgage options is transaction cost, not a factor in simple options pricing models but central in mortgage refinancings. Consider for a moment the notion of a mortgage refinancing option in the absence of transaction costs. Any movement of market rates below the mortgage coupon rate could trigger instantaneous refinancing. The debtor's own uncertainty or forecast about future mortgage rates would not matter to his refinancing decision, given the level of market rates. Transactions costs, however, cause the debtor to limit the frequency of his refinancing. Interest rate uncertainty becomes important within this framework, since, for example, it provides more expected return to waiting before incurring the fixed transaction cost. ${ }^{2}$ Figure 2 illustrates the importance of transaction costs. The figure shows again the vega

model. The face value of the amortizing bond (the mortgage) is $\$ 100$. The model asserts that interest rates follow a geometric Brownian motion with constant expected growth $\mu$ and constant volatility $\sigma$. In our binomial simulations, the contract rate on the mortgage is $0.08, \mu$ is constant at 0.05 , and the time step is one year (that is, $\Delta t=1$ ). Moreover, the initial value of the interest rate and volatility are changed by the increment of 0.001 (with the average volatility equaling to 0.15 ).

2 At the same time, more actual rate movement is expected to increase the intrinsic value gains from refinancing. In retrospect, therefore, a period of market volatility should correlate with high refinancing activity. But, looking forward at a point in time with a given spread between coupon and market rates, a higher expected volatility should reduce the current likelihood of refinancing rather than waiting. 
of the 2-year mortgage with a face value of $\$ 100$ and zero transaction costs (the solid curve in Figure 1) and the vega of a 2-year mortgage option with a transaction costs of $\$ 0.60$. As expected, higher transaction costs lower the value of the mortgage call. At the same time, the vega threshold rises, reflecting the additional cost of refinancing.

For at-the-money mortgage options, it must hold that the intrinsic value is equal to the refinancing threshold. To illustrate this property in mortgages consider again the numerical example presented in Figure 2. From the binomial tree simulations, we can calculate the actual at-the-money value of the call to be $\$ 0.195$ when transaction costs are zero. An alternative way to approximate the value of call option is to find the maximum of the vega, which identifies the point at which the call is at the money. From the figure, we observe that the vega peaks around $\$ 0.210$. Since transaction costs are zero, this number can serve as an alternative estimate for the actual value of the option. ${ }^{3}$

When transaction costs are set equal to 60 cents, the binomial estimate of the at-themoney value of the call is $\$ 0.051$. Looking at the figure again, we find that in this case the vega reaches a maximum around $\$ 0.655$ (the estimate of the refinancing threshold). The vega estimate for the value of the option is therefore $\$ 0.655-\$ 0.6=\$ 0.055$. In short, we have demonstrated that a simple approach to locating the refinancing threshold would be to find where the mortgage vega peaks in absolute value. These peaks should depend in part on the individual household's characteristics that affect its transaction costs. In the following discussion, we will develop an approach to empirically identifying these vega threshold values.

3 Of course, one can improve the precision of the binomial and vega estimates by choosing smaller time steps. As noted previously, the vega estimate will become slightly more biased for higher maturities. However, we found that the vega approximation continues to be fairly accurate even at higher expected holding periods. 
We have illustrated above that the (negative) effect of interest rate volatility on refinancing probability will be strongest for loans where the costs and benefits of refinancing are close to balance (or, more precisely, where they are just tipped in favor of refinancing). At that point, the downside risk of postponing the transaction is very limited and little affected by increased volatility. At that same point, however, the expected gain from waiting is clearly increased by heighten volatility. Further away from the refinancing threshold, where the net benefit of refinancing is greater, the asymmetry of the upside and downside volatility effects becomes diluted. Away from the threshold, the expected loss from scenarios in which rates go back up is greater. Indeed, if rates stand sufficiently far below the current coupon, refinancing will be overwhelmingly attractive, and the influence of volatility will be correspondingly trivial.

In the next section, we will show that this logic is complicated only slightly by the fact that higher volatility will also increase the attractiveness of the prepayment option on the replacement financing. The (positive) effect of market volatility on this replacement option will be reflected as an increase in the option-adjusted spread charged in the market. The option on the pre-existing loan, in contrast, also increases in value to the debtor, but its cost is locked in as long as he does not refinance. Since it is well out of the money, the effect of volatility on the value of the replacement option should be considerably smaller than the effect of volatility on the fair value of the existing option. On balance, after controlling for the partial effect of volatility on the difference between existing and current market mortgage rates, the remaining independent effect of volatility on the refinancing probability will be negative and strongest for loans very near their refinancing thresholds.

\section{A STATISTICAL MODEL OF MORTGAGE PREPAYMENT}

The theoretical mortgage option model considered above can be modified into an econometric specification. The net benefit from refinancing is influenced by a broad range 
of factors: the intrinsic value of the mortgage, the time value of the call, and a variety of frictional costs that may stem from the borrower's credit quality or available equity in the property. Let $B_{t i}^{*}$ represent the net benefit from refinancing for the $\mathrm{i}$-th individual in month (t). Consistent with equation (3), we can define the net benefit from refinancing as:

$$
B_{t i}^{*}=P^{N C}\left(T, t, r_{0 i}\right)-P^{N C}\left(T, t, r_{m t i}\right)-T C\left(p_{t i}, c_{t i}, \ell_{t i}\right)-\nu\left(T, t, \sigma_{t}\right) .
$$

Although $B_{t i}^{*}$ is not directly observable, we observe a vector $x_{t i}$. that includes the factors that determine the net benefit of refinancing (e.g., the volatility, remaining maturity, original and prevailing mortgage rates, creditworthiness, etc.). We can therefore express the net benefit from refinancing as a function of these explanatory variables, of the general form

$$
B_{t i}^{*}=g\left(x_{t i} \cdot \beta\right)+\epsilon_{t i}
$$

where $g(\cdot)$ allows for the possibility that the effect of $x_{t i}$. may be nonlinear, and the random error $\epsilon_{t i}$ measures unobserved idiosyncratic net costs or benefits to individual homeowners. Define $y_{t i}$ to be a binary variable:

$$
\begin{array}{llll}
y_{t i}=1 & \text { if } & B_{t i}^{*}>0 & \text { (homeowner refinances) } \\
y_{t i}=0 & \text { if } & \text { otherwise } & \text { (no refinancing occurs) } .
\end{array}
$$

Together equations (5.1)-(5.3) represent an econometric model of binary choice. The parameter vector of the binary choice model $\beta$ can be estimated by the method of maximum likelihood. We will use maximum likelihood logit analysis to estimate the effect of different explanatory variables on the willingness to refinance (for more details, see Maddala (1983) and Green (1993)). The discrete-choice model has been applied extensively in the estimating factor influencing prepayments (Cunningham and Capone 1990; Archer, Ling, and McGill 1996; Peristiani, Bennett, Monsen, Peach, and Raiff 1997). Alternatively, one 
can use hazard analysis to investigate the decision to prepay (Caplin, Freeman, and Tracy 1997; Follain, Ondrich, and Sinha 1997; Bennett, Peach, and Peristiani 1998). Hazard models are sometimes preferred to discrete-choice Logit or Probit models because they estimate the rate at which an event will occur given that it has not occurred until that point in time. In the current framework, however, we use a discrete-choice model because, as will be shown in the next section, the marginal effects of this specification are more consistent with option theory.

The probability of prepayment in a given month can be defined as:

$$
S M M_{t i}=P(\mathrm{i}-\text { th homeowner prepays in month }(\mathrm{t}))=P\left(y_{t i}=1\right)=\Lambda\left(x_{t i} \cdot \beta\right)
$$

where $\Lambda(\cdot)$ represents the logistic cumulative distribution function. This monthly prepayment measure is usually referred to in the mortgage finance literature as the single monthly mortality rate (SMM).

\subsection{Inferring the Vega from a Prepayment Probability}

The logistic regression estimates the effect of the call option indirectly through the relationship between volatility and the probability of refinancing. We will argue, however, that the marginal effect of volatility on the probability of refinancing relates to the underlying vega of the call option. It is worth noting that within this framework the prepayment vega — where the effects of volatility on the probability of refinancing is greatest — can be understood as corresponding to the point where the effects of volatility on the net benefits of refinancing are greatest. To see how, consider the probability of prepayment, measured as a single monthly mortality

$$
S M M=F(x, \nu(T, t, \sigma))
$$

where $(x)$ includes all exogenous variables affecting the probability of refinancing besides the net value of the call. We assume that $F(\cdot)$ is a continuous differentiable function. 
Applying the chain rule, we can show that ceteris paribus

$$
\frac{\partial S M M}{\partial \sigma}=v(T, t, \sigma)=F_{\sigma} \frac{\partial \nu(T, t, \sigma)}{\partial \sigma} \propto-\frac{\partial \nu(T, t, \sigma)}{\partial \sigma} .
$$

such that $F_{\sigma}$ is the derivative of $F(\cdot)$ with respect to $\sigma$. Here, we expect that $F_{\sigma}$ is negative. Equation (7) shows that the sensitivity of the monthly prepayment to changes in volatility (hereafter, referred to as prepayment vega) is proportional to the vega of the call option. ${ }^{4}$ In turn, this result suggests that the prepayment vega (now a convex function) should achieve a minimum when the option to refinance is roughly at the money. Consequently, one can view a prepayment vega in the same way as an option vega.

In the logit model, the marginal effect of volatility is

$$
\frac{\partial S M M}{\partial \sigma}=v\left(x_{t i \cdot} \beta\right)=g_{\sigma} \Lambda\left(x_{t i \cdot} \beta\right)\left(1-\Lambda\left(x_{t i} \cdot \beta\right)\right)
$$

where $g_{\sigma}$ denotes the partial derivative of $g(\cdot)$ with respect to $\sigma$ and $\Lambda(\cdot)$ represents the logistic cumulative distribution. A property of the binary choice models (logit or probit) is that the marginal effect of volatility takes a functional form that is consistent with the properties of the option vega. An interesting special case is the linear logit model, that is, $g\left(x_{t i} \cdot \beta\right)=x_{t i} \cdot \beta$. We can show in this case that the prepayment vega attains a minimum when the probability of prepayment is 0.5 (e.g., $\left.\Lambda\left(x_{t i} \cdot \beta\right)=0.5\right) .{ }^{5}$ Therefore, in the linear

4 Although $\nu(T, t, \sigma)$ represents the net value between the existing and new option, the vega is approximately equal to the vega of the existing option. Mathematically, we can show that

$$
\frac{\partial \nu(T, t, \sigma)}{\partial \sigma}=\frac{\partial V\left(T, t, \sigma, r_{0} \mid r_{m}\right)}{\partial \sigma}-\frac{\partial V\left(T, t, \sigma, r_{m} \mid r_{m}\right)}{\partial \sigma} \approx \frac{\partial V\left(T, t, \sigma, r_{0} \mid r_{m}\right)}{\partial \sigma}
$$

The vega of the new option is very small because the new option is basically deep out of the money.

5 In the linear case, equation (8) reduces to $v=\beta_{\sigma} \Lambda(1-\Lambda)$, where $\beta_{\sigma}$ represents the 
case, a mortgage holder is considered to be at the money when the likelihood of refinancing equals 0.5. While this simple case is appealing, we prefer the more general nonlinear specification, which allows the threshold location and the corresponding refinancing probability at that turning point to be determined more flexibly.

\subsection{Estimating the Refinancing Threshold: Some Adjustments}

Since the prepayment vega is expected to be greatest near the point where the costs and benefits of refinancing are balanced, we should be able to approximate this threshold by observing where volatility has its largest impact on the refinancing probability. Using an appropriately specified statistical model, we can estimate the vega threshold as a function of the variables that determine refinancings.

The intrinsic value of the mortgage plays a key role in determining the vega threshold. As shown above, this measure computes the noncallable value of the loan using the contract rate on the existing loan $\left(r_{0}\right)$ and the prevailing market rate $\left(r_{m}\right)$. Richard and Roll (1989) propose a simple measure of the intrinsic value. The authors note that, since a mortgage obligation is an annuity, the intrinsic worth of a mortgage is given by the ratio of the two annuities, that is,

$$
\alpha_{t i}=\frac{d\left(r_{m t i}, T, t\right)}{d\left(r_{0 i}, T, t\right)}=\left(\frac{r_{0 i}}{r_{m i}}\right)\left(\frac{1-\left(1+r_{m t i}\right)^{t-T}}{1-\left(1+r_{0 i}\right)^{t-T}}\right),
$$

where $d(r, T, t)=\left[1-(1+r)^{t-T}\right] / r$. For all observations in our sample, the original rate for the i-th owner $\left(r_{0 i}\right)$ is measured by the national average commitment (contract) rate on fixed rate loans for the month the loan was closed. This is the so-called A paper rate or the rate available to the best credit risks. Similarly, the prevailing market rate for the i-th mortgage holder at month $(\mathrm{t})\left(r_{m t i}\right)$ is also the national average A paper contract rate at month (t).

marginal of $g\left(x_{t i} \cdot \beta\right)$ with respect to $\sigma$. Since $\beta_{\sigma}$ is a negative constant, the prepayment vega $v$ is minimized when $\Lambda=0.5$. 
Using the Richard-Roll measure, we rearrange (3) above, such that all variables that are directly observable are on the left hand side of the decision rule: ${ }^{6}$

$$
d\left(r_{m t i}, T, t\right)-d\left(r_{0 i}, T, t\right)-T C\left(p_{t i}\right)>T C\left(c_{t i}, \ell_{t i}\right)+\nu(T, t, \sigma),
$$

where $T C\left(p_{t i}\right)$ represents the points and fees paid by the borrower. Dividing both sides of the equation by $d\left(r_{0 i}, T, t\right)$, we obtain

$$
\alpha_{t i}-1-\frac{T C\left(p_{t i}\right)}{d\left(r_{0 i}, T, t\right)}>\frac{T C\left(c_{t i}, \ell_{t i}\right)+\nu\left(T, t, \sigma_{t}\right)}{d\left(r_{0 i}, T, t\right)}
$$

or

$$
I_{t i}>h_{t i}
$$

The refinancing hurdle $h_{t i}$ depends on credit, collateral, option replacement cost, and other variables, and $I_{t i}$ denotes the intrinsic value of refinancing, net of points and fees. A borrower is at the money when $I_{t i}$ equals $h_{t i}$. A simple estimate of this at-the-money threshold $h_{t i}$ is given by:

$$
\hat{h}_{t i}=\min v\left(x_{t i} \cdot \hat{\beta}\right)
$$

where $v\left(x_{t i}, \beta\right)$ is defined by equation (8). In turn, the actual refinancing hurdle can be estimated by

$$
\hat{H}_{t i}=T C\left(c_{t i}, \ell_{t i}\right)+V\left(T, t, \sigma_{t i}\right)=d\left(r_{0 i}, T, t\right) \hat{h}_{t i} .
$$

Note that the estimator $\hat{H}_{t i}$ does not distinguish the different parts of the refinancing hurdle. However, one can separate out the value of the call option from the transaction cost

${ }^{6}$ In our case, we fully observe the intrinsic value of the mortgage $\alpha_{t i}$ and the transaction cost of points and fees $p_{t i}$. Although we have information on credit ratings and home equity, we cannot directly determine the related transaction costs. Of course, if these costs (e.g., $T C\left(c_{t i}\right)$ and $\left.T C\left(\ell_{t i}\right)\right)$ were also well-defined, they can be subtracted from the intrinsic value as well. 
by choosing certain convenient simulation scenarios. We know for instance that borrowers who are not credit- or collateral-constrained are not likely to pay a transaction premium (other than customary points and fees), meaning that the transaction $\operatorname{costs} T C\left(c_{t i}, \ell_{t i}\right)$

would be small. As a result, $\hat{H}_{t i}$ would measure primarily the option replacement cost. Similarly, we expect the value of the option replacement cost to be negligible if volatility is small. Thus, $\hat{H}_{t i}$ would most likely represent the cost of inadequate collateral or credit when volatility is small.

The process of estimating the implicit refinancing hurdled faced by any holder of a mortgage option can summarized in four key steps:

Step 1: Calculate the net intrinsic value of the mortgage $I_{t i}$ from equation (10).

Step 2: Use $I_{t i}$ along with a measure of volatility and other explanatory variables to estimate a nonlinear version of the logit model for refinancing (equation (5)). Although the functional form of $g\left(x_{t i} \cdot \beta\right)$ is arbitrary, it should be flexible enough to capture the interaction of volatility with all other independent variables.

Step 3: Given the maximum likelihood estimate of the parameter vector $\beta$, generate simulated values of the prepayment vega $v\left(x_{t i} \cdot \beta\right)$ (equation $\left.(8)\right)$ for different scenarios of volatility, loan maturity, credit quality, and home equity.

Step 4: Identify the minimum value of the prepayment vega and solve for the implicit value of the refinancing hurdle (equations (12) and (13)).

\section{RESULTS}

\subsection{Data and Model Specification}

The data was provided by the Mortgage Research Group (MRG) of Jersey City, New Jersey, which entered into a strategic alliance with TRW a large national credit bureau. Our final sample includes about 13,000 transactions from these four geographic regions 
(New York /New Jersey, Central Florida, Chicago, and Los Angeles). The sample consists of fixed-rate loans in which the property was purchased after 1984 and was subsequently refinanced or the status of the loan remained unchanged as of the end 1994. In the final step, the snapshots of credit histories were linked to a random sample of these properties by MRG. Using this cross-sectional sample, we constructed an unbalanced panel by adding a time dimension to the data. The resulting panel represents the experience of individual mortgage loans from the time of purchase to the time of refinancing or the end of 1994 for mortgages that did not prepay. Each monthly episode for this individual was matched with to an array of time-varying characteristics: prevailing mortgage rate, volatility, current loan-to-value of the property, and transactions cost. The resulting panel consists of approximately 560,000 observations, of which about 4,400 resulted eventually in a refinancing.

We apply the four-step procedure outlined in the previous section to our sample of mortgage refinancings. The logit model is estimated using a nonlinear specification, which consists of higher polynomial powers and cross-product terms of the exogenous information. ${ }^{7}$ This specification is quite useful in capturing the nonlinear aspects of the call option. In the logit model, the binary dependent variable $y_{t i}$ represents the decision to refinance (one if the mortgage is refinanced and zero otherwise). The explanatory vector $x_{t i}$. includes: $(1)$ the intrinsic value of the mortgage $\left(\alpha_{t i}\right) ;(2)$ interest rate volatility

7 This specification is similar to a Taylor expansion approximation. Suppose that the explanatory vector includes $\mathrm{K}$ variables $\left(x_{1}, \ldots, x_{K}\right)$. The nonlinear specification employed in our analysis is:

$$
B^{*}=\beta_{0}+\sum_{i=1}^{K} \beta_{1 i} x_{i}+\sum_{i=1}^{K} \beta_{2 i} x_{i}^{2}+\sum_{i=1}^{K} \beta_{3 i} x_{i}^{3}+\sum_{i, j} \sum_{i \neq j} \gamma_{i j} x_{i} x_{j}+\epsilon .
$$


measured by the implied volatility of the option price of a 10-year Treasury note futures contract $\left(\sigma_{t}^{\iota}\right)$; (3) TRW credit rating measure of the homeowner $\left(c_{t i}\right)$; (4) post-origination loan-to-value ratio $\left(\ell_{t i}\right) ;(5)$ point and fees (as percent of loan value) (6) age of the loan $\left(\tau_{t i}\right)$; and $(7)$ size of the mortgage loan $\left(s_{t i}\right) .^{8}$

Estimates of the nonlinear model used in simulations are more difficult to interpret and are therefore not presented in this paper. Table 1, however, summarizes the linear logit specification. The results of the linear specification strongly support the view that a homeowner's decision to refinanced is influenced by the intrinsic value of the mortgage. In particular, the coefficient on the annuity ratio $\alpha_{t i}$ is positive and highly significant. As expected, the effect of points and fees is negative and strongly significant, confirming that higher transaction costs raise the refinancing hurdle faced by homeowners. The current loan-to-value ratio coefficient is negative and very significant. A strong statistical significance of loan-to-value signifies that homeowners with insufficient collateral are unable to prepay their mortgage loan even if economic conditions are in their favor. These results bolster the findings of Caplin, Freeman, and Tracy (1997) and Archer, Ling, McGill (1996),

8 In computing the net intrinsic value of the mortgage, we assume an existing mortgage rate $r_{0 i}$ and a current market rate $r_{m t i}$ at which the borrower can refinance. In practice, households can choose from a menu of mortgage rates and points. This creates a problem in comparing the coupon rate on the existing loan the currently prevailing market rate. To deal with this potential inconsistency, we estimated $r_{0 i}$ by the average Fredie Mac commitment rate on a 30-year fixed-rate mortgages for the month that the loan was initially closed. Similarly, we estimated $r_{m t i}$ by the commitment rate for the month that the loan was refinanced. Finally, transaction costs are measured by points and fees charges on conventional fixed-rate loans closed. This monthly series is compiled by the Federal Housing Finance Board. 
who also find evidence that home equity is a critical factor in the decision to refinance. Finally, to a lesser extent, the linear model suggests that a borrower's creditworthiness has also an adverse effect on the probability of refinancing.

An important finding of our analysis is that the marginal effect of volatility on the likelihood of prepayment is negative. The negative relationship is key to our empirical analysis because without it the prepayment vegas would not be convex. This result affirms that the value of the call increases when the volatility of the noncallable asset is expected to rise. Higher expected volatility encourages borrowers to postpone refinancing because the benefit from waiting to refinance would be greater in the future.

\subsection{Estimates of the Refinancing Threshold}

The logit model is estimated for three different expected holding period scenarios: 15 years, 20 years, and 30 years. Using the maximum likelihood estimates of $\beta$, we estimate the prepayment vega $v\left(x_{t i} . \beta\right)$ by simulating the exogenous variables $x_{t i}$. over a wide range of values. Figure 3 illustrates graphically the search process for determining the strike price of the prepayment vega. The curves in the graph represent the prepayment vega for three different holding period scenarios. In all three cases, borrowers are assumed to have unblemished credit histories and a loan-to-value ratio of 70 percent. The grid search for finding the minimum of $v\left(x_{t i} . \beta\right)$ is done at increments of 0.01 of the value of $I_{t i}$. As seen in the figure, the prepayment vega curve for the 15-year scenario (solid curve) is minimized around $\hat{H}_{t i}=2.3$ percent. The refinancing hurdle is higher for a lengthier expected holding horizon $\left(\hat{H}_{t i}\right.$ equals 3.8 percent and 6.3 percent for the 20 -year and 30 year periods, respectively).

Table 2 summarizes the estimates of the refinancing threshold $h_{t i}$ (as a percent of the original loan value) for a broad range of simulations. Our numerical simulations assume: (a) mortgage holders have either unblemished or poor credit rating; (b) the current loan- 
to-value ratio $\ell_{t i}$ takes the values of 40 percent, 70 percent, or 100 percent; and (c) the implied volatility varies from 4 basis points to 8 basis points. The remaining explanatory variables are evaluated at their mean.

The simulation results are consistent with reasonable behavior by homeowners. The refinancing thresholds rise with the expected life of the mortgage and the value of the call option increases with volatility. Typically, a homeowner in our sample has a spotless credit history and a loan-to-value ratio around 70 percent. At the average volatility of 6 basis points, the financing threshold for this mortgage holder is 4.44 percent. Because borrowers in our sample paid on average an additional 2 percentage points in fees (as a percent of the loan value), the intrinsic gain from refinancing would have to be greater than 6.44 percent of the value of mortgage loan to warrant refinancing.

The refinancing threshold also depends on credit quality and collateral value. Note that the effect of collateral is magnified at higher holding periods. At a 15-years holding horizon, a homeowner with a loan-to-value ratio of 100 percent has to pay 50 basis points more in refinancing costs than the typical homeowner. This "surcharge" further rises to 80 basis points for a loan maturing in 30 years. This big jump in costs, however, should not be construed that a homeowner with a 30 -year loan is at a handicap. Table 3 recalculates the refinancing threshold in terms of the coupon spread between the original mortgage rate $r_{0}$ and the prevailing market rate $r_{m} \cdot{ }^{9}$ As seen from the table, the coupon rate differential

9 At this coupon spread, the net present value of the mortgage is equal to the refinancing threshold (see equation (9)). This point represents the minimum interest rate differential that can justify refinancing. In our calculations, we assume: the average age of the mortgage loan is $t=4$ years; the average cost of points and fees $p_{t i}$ is 2 percent (as a percent of loan value); and the original coupon rate is 10 percent, which is the average contract rate of the sample. 
needed to trigger a prepayment is larger for shorter maturities. Our findings also affirm the importance of interest rate uncertainty as the coupon spread needed to justify refinancing rises with the level of implied volatility. Overall, we find that a delinquency would add about 6 basis points to the homeowner's mortgage rate. ${ }^{10}$ Furthermore, a collateralconstrained borrower would have to pay about 10 basis points more for refinancing than the average homeowner.

\section{SUMMARY AND CONCLUSION}

This paper develops a method of computing the thresholds at which individuals will refinance mortgage loan. In effect, we measure how large a change in the present value of the debt is required to make it worth the expense of carrying out the transaction, conditional not only on market conditions but on individual borrower characteristics as well. Since refinancing has considerable transactions costs, including the cost of securing new funding, the exercise of the refinancing option will depend on a variety of factors outside the standard option valuation theory. How large the threshold is for a particular household, for instance, will depend on its credit rating and its available collateral. Similar principles would apply for businesses.

To compute these conditional thresholds, we take advantage of the prediction from option theory that volatility will have its largest effect when an option is near the money. Furthermore, we show that this point of the largest effect corresponds to a state where the conditional probability of refinancing exceeds a critical value. We estimate logit equa-

10 On the surface, the effect of credit appears to be small. We should note, however, that the credit variable used in our analysis represents the worst ever rating across all credit lines some of which (for example, retail derogatories) are deemed as less flagrant. Although the worst ever snap shot is a conservative measure that may underestimate the importance of credit, it is nevertheless more reliable than other reported measures. 
tions using a panel data set on house refinancings, market volatility and interest rates, credit ratings, collateral values, financing points and fees, and other household and market data. We locate the refinancing spreads at which the effect of volatility on refinancing probabilities is optimized. These are the refinancing thresholds, and they vary in size as expected conditional on the credit, collateral, remaining maturity, and other measurable characteristics. In short, we are able to compute in a positive (as opposed to normative) manner how large a spread it takes to precipitate refinancings for different categories of homeowners. 


\section{APPENDIX}

\section{The Vega of a European Call}

Consider a simple European call option on a zero-coupon bond or stock. In the Black-Scholes framework, the value of the call depends on the current asset price (S), the maturity date $(\mathrm{T})$, the strike price $(\mathrm{X})$, the underlying risk-free interest rate $(\mathrm{r})$, and the volatility of the price of bond $(\sigma)$. Mathematically, $V_{E}(S, T, t, r, \sigma)$. Although the strike price X may not be observable, we can determine the moneyness of an option by considering its sensitivity to changes in volatility. This approach is applied extensively in designing optimally hedged portfolios. The value of an option is positively related to the volatility of the underlying asset. The effect of volatility, however, is strongest when the option is near the money. In the Black-Scholes case, the partial derivative of the value of the call with respect to volatility (the vega) is equal to

$$
v_{E}(z, \sigma)=\frac{\partial V_{E}}{\partial \sigma}=S \sqrt{T-t} \phi(z, \sigma),
$$

where $\phi(\cdot)$ represents the standard normal density function and $\mathrm{z}$ is a vector of other factors other than volatility affecting the call value (see Hull (1993)). Figure A1 presents the vega of the European call option for different values of the bond price S. As seen, the vega is always positive, although small for deeply away from the money positions. The vega of the European call option reaches a maximum at the point where

$$
S_{E}^{*}=X e^{-r(T-t)} e^{0.5(T-t) \sigma^{2}} .
$$

Since $e^{0.5(T-t) \sigma^{2}}$ would roughly equal to 1 for reasonable values of (T-t) and $\sigma$, the vega of a European call is maximized approximately at the forward price of the strike price. This result holds also for more general models. For instance, in Merton's European Call model with a continuous dividend $\delta$, the vega is

$$
v_{E}(z, \sigma)=S \sqrt{T-t} e^{-\delta(T-t)} \phi(z, \sigma) .
$$


Once again, one can show that the vega attains a maximum at

$$
S_{E}^{*}=X e^{-r(T-t)} e^{0.5 \sigma^{2}(T-t)} e^{-\delta(T-t)} .
$$




\section{REFERENCES}

[1] Archer, Wayne, David Ling, and Gary McGill. "The Effect of Income and Collateral Constraints on Residential Mortgage Terminations," Regional Science and Urban Economics 26 (1996), 235-261.

[2] Bennett, Paul, Richard Peach, and Stavros Peristiani. "Structure Change in the Mortgage Market and the Propensity to Refinance," Federal Reserve Bank of New York Research Paper No. 9736, November 1997.

[3] Caplin, Andrew, Charles Freeman, and Joseph Tracy. "Collateral Damage: How Refinancing Constraints Exacerbate Regional Recessions," Journal of Money, Credit, and Banking 29 (November 1997), 496-516.

[4] Chen, Andrew, and David C. Ling. "Optimal Mortgage Refinancing with Stochastic Interest Rates," Journal of the American Real Estate and Urban Economics Association 17 (1989), 278-299.

[5] Cunningham, Donald F., and Charles A. Capone. "The Relative Termination Experience of Adjustable to Fixed-Rate Mortgages," Journal Finance 45 (1990), 1687-1703.

[6] Follain, James R., James O. Scott, TL Tyler Yang. "Microfoundations of a Mortgage Prepayment Function," Journal of Real Estate and Economics 5 (1992), 197-217.

[7] Follain, Jan Ondrich, and Gyan P. Sinha. "Ruthless Prepayment? Evidence from Multifamily Mortgages," Journal of Urban Economics 41 (1997), 78-101.

[8] Green, Willian H. Econometric Analysis. New York: Macmillan Publishing Company, 1993.

[9] Hall, Arden R. "Valuing the Mortgage Borrower's Prepayment Option," Journal of the American Real Estate and Urban Economics Association 13 (1985), 229-247. 
[10] Hull, John. Options, Futures, and Other Derivative Securities. Englewood Cliffs, New Jersey: Prentice Hall, 1993.

[11] Kolb, Robert W. Understanding Options. New York: John Wiley, 1995.

[12] Maddala, G. Limited Dependent and Qualitative Variables in Econometrics. New York: Cambridge University Press, 1983.

[13] Peristiani, Stavros, Paul Bennett, Gordon Monsen, Richard Peach, and Jonathan Raiff. "Effects of Household Creditworthiness on Mortgage Refinancings," Journal of Fixed Income 7 (December 1997), 7-21.

[14] Quigley, John M. and Robert Van Order. "Efficiency in the Mortgage Market: The Borrower's Perspective," AREUEA Journal 18 (1990), 237-252.

[15] Rendleman, R., and B. Bartter. "The Pricing of Options of Debt Securities," Journal of Financial and Quantitative Analysis 15 (March 1980), 11-24.

[16] Richard, Scott F., and Richard Roll. "Prepayments on Fixed-Rate Mortgage-backed Securities," The Journal of Portfolio Management 15 (Spring 1989), 73-82.

[17] Yang, Tyler T., and Brian M. Maris. "Mortgage Prepayment With an Uncertain Holding Period," Journal of Real Estate Finance and Economics 12 (1996), 179-194. 
TABLE 1. LOGIT ESTIMATES FOR THE DECISION TO REFINANCE

\begin{tabular}{lll}
\hline Variable & Coefficient & Chi-square \\
& & Statistic \\
\hline CONSTANT & $1.721^{* * *}$ & 8.8 \\
DUM-NY & $-0.750^{* * *}$ & 178.3 \\
DUM-IL & $-1.368^{* * *}$ & 423.3 \\
DUM-FL & 0.093 & 2.7 \\
$c_{t i}$ & $-0.001^{* * *}$ & 46.3 \\
$\alpha_{t i}$ & $0.020^{* * *}$ & 76.8 \\
$\ell_{t i}$ & $-0.024^{* * *}$ & 1233.1 \\
$\sigma_{t}^{\iota}$ & $-0.142^{* * *}$ & 46.3 \\
$p_{t i}$ & $-4.774^{* * *}$ & 1286.5 \\
$\tau_{t i}$ & $0.668^{* * *}$ & 85.7 \\
$\tau_{t i}^{2}$ & $-0.105^{* * *}$ & 28.4 \\
$\tau_{t i}^{3}$ & 0.002 & 0.9 \\
$s_{t i}$ & $0.155^{* * *}$ & 30.7 \\
\hline Refinancings & & 4430 \\
Nonrefinacings & & 564289 \\
Chi-square of Model & 6612.1 \\
Concordant Ratio & & 77.8 \\
\hline \hline
\end{tabular}

NOTES: DUM-NY, DUM-IL, DUM-FL are dummy variables indicating loans in New York, Illinois, and Florida, respectively; $\alpha_{t i}=$ intrinsic value of the mortgage loan; $p_{t i}=$ points and fees (as percent of the loan value); $\ell_{t i}=$ current loan-to-value ratio (percent); $c_{t i}$ is the worst delinquency ever; $\sigma^{\iota}$ represents the implied price volatility on options on the 10-year treasury note futures (basis points); $\tau_{t i}=$ age of the loan (in months) $; s_{t i}=$ logarithm of original loan balance. The symbols $(* * *),(* *)$, and $(*)$ indicate statistical significance at the 1-, 5-, and 10-percent level, respectively. 
TABLE 2. THE IMPLIED REFINANCING THRESHOLD (PERCENT OF ORIGINAL LOAN VALUE, $\left.h_{t i}\right)$

\begin{tabular}{|c|c|c|c|c|}
\hline & & 40 & $\begin{array}{l}\mathrm{LTV}, \ell_{t i} \\
70\end{array}$ & 90 \\
\hline \multicolumn{5}{|l|}{15 YEARS } \\
\hline VOLATILITY, $\sigma^{\iota}$ & CREDIT, $c_{t i}$ & & & \\
\hline 4 & $\begin{array}{l}\text { GOOD } \\
\text { POOR }\end{array}$ & $\begin{array}{l}2.12 \\
2.32\end{array}$ & $\begin{array}{l}2.53 \\
2.73\end{array}$ & $\begin{array}{l}3.03 \\
3.23\end{array}$ \\
\hline 5 & $\begin{array}{l}\text { GOOD } \\
\text { POOR }\end{array}$ & $\begin{array}{l}3.03 \\
3.33\end{array}$ & $\begin{array}{l}3.54 \\
3.74\end{array}$ & $\begin{array}{l}3.94 \\
4.14\end{array}$ \\
\hline 6 & $\begin{array}{l}\text { GOOD } \\
\text { POOR }\end{array}$ & $\begin{array}{l}4.04 \\
4.34\end{array}$ & $\begin{array}{l}4.44 \\
4.75\end{array}$ & $\begin{array}{l}4.95 \\
5.15\end{array}$ \\
\hline 7 & $\begin{array}{l}\text { GOOD } \\
\text { POOR }\end{array}$ & $\begin{array}{l}5.15 \\
5.45\end{array}$ & $\begin{array}{l}5.56 \\
5.96\end{array}$ & $\begin{array}{l}6.06 \\
6.36\end{array}$ \\
\hline 8 & $\begin{array}{l}\text { GOOD } \\
\text { POOR }\end{array}$ & $\begin{array}{l}6.87 \\
7.26 \\
\end{array}$ & $\begin{array}{l}7.27 \\
7.69 \\
\end{array}$ & $\begin{array}{l}7.68 \\
8.08 \\
\end{array}$ \\
\hline \multicolumn{5}{|l|}{20 YEARS } \\
\hline 4 & $\begin{array}{l}\text { GOOD } \\
\text { POOR }\end{array}$ & $\begin{array}{l}2.93 \\
3.23\end{array}$ & $\begin{array}{l}3.54 \\
3.84\end{array}$ & $\begin{array}{l}4.14 \\
4.44\end{array}$ \\
\hline 5 & $\begin{array}{l}\text { GOOD } \\
\text { POOR }\end{array}$ & $\begin{array}{l}4.24 \\
4.55\end{array}$ & $\begin{array}{l}4.85 \\
5.15\end{array}$ & $\begin{array}{l}5.45 \\
5.76\end{array}$ \\
\hline 6 & $\begin{array}{l}\text { GOOD } \\
\text { POOR }\end{array}$ & $\begin{array}{l}5.56 \\
5.86\end{array}$ & $\begin{array}{l}6.06 \\
6.46\end{array}$ & $\begin{array}{l}6.67 \\
7.07\end{array}$ \\
\hline 7 & $\begin{array}{l}\text { GOOD } \\
\text { POOR }\end{array}$ & $\begin{array}{l}6.97 \\
7.37\end{array}$ & $\begin{array}{l}7.47 \\
7.88\end{array}$ & $\begin{array}{l}8.08 \\
8.48\end{array}$ \\
\hline 8 & $\begin{array}{l}\text { GOOD } \\
\text { POOR }\end{array}$ & $\begin{array}{l}8.99 \\
9.49 \\
\end{array}$ & $\begin{array}{l}9.49 \\
10.01 \\
\end{array}$ & $\begin{array}{l}10.10 \\
10.61 \\
\end{array}$ \\
\hline \multicolumn{5}{|l|}{30 YEARS } \\
\hline 4 & $\begin{array}{l}\text { GOOD } \\
\text { POOR }\end{array}$ & $\begin{array}{l}4.24 \\
4.55\end{array}$ & $\begin{array}{l}5.15 \\
5.45\end{array}$ & $\begin{array}{l}5.96 \\
6.36\end{array}$ \\
\hline 5 & $\begin{array}{l}\text { GOOD } \\
\text { POOR }\end{array}$ & $\begin{array}{l}5.96 \\
6.46\end{array}$ & $\begin{array}{l}6.87 \\
7.27\end{array}$ & $\begin{array}{l}7.78 \\
8.18\end{array}$ \\
\hline 6 & $\begin{array}{l}\text { GOOD } \\
\text { POOR }\end{array}$ & $\begin{array}{l}7.58 \\
8.08\end{array}$ & $\begin{array}{l}8.48 \\
8.99\end{array}$ & $\begin{array}{l}9.39 \\
9.90\end{array}$ \\
\hline 7 & $\begin{array}{l}\text { GOOD } \\
\text { POOR }\end{array}$ & $\begin{array}{l}9.29 \\
9.80\end{array}$ & $\begin{array}{l}10.10 \\
10.71\end{array}$ & $\begin{array}{l}11.01 \\
11.52\end{array}$ \\
\hline 8 & $\begin{array}{l}\text { GOOD } \\
\text { POOR }\end{array}$ & $\begin{array}{l}11.31 \\
12.10\end{array}$ & $\begin{array}{l}12.12 \\
12.84\end{array}$ & $\begin{array}{l}12.83 \\
13.54\end{array}$ \\
\hline
\end{tabular}

NOTES: $\ell_{t i}$ represents the current loan-to-value ratio (percent); $c_{t i}$ is the worst delinquency ever $(\mathrm{GOOD}=$ unblemished credit, $\mathrm{POOR}=$ homeowner has defaulted $) ; \sigma^{\iota}$ represents the implied price volatility on options on the 10-year treasury note futures (basis points). 
TABLE 3. THE IMPLIED MINIMUM COUPON RATE DIFFERENTIAL (basis points)

\begin{tabular}{|c|c|c|c|c|}
\hline & & 40 & $\begin{array}{l}\text { LTV, } \ell_{t i} \\
70\end{array}$ & 90 \\
\hline \multicolumn{5}{|l|}{15 YEARS } \\
\hline VOLATILITY, $\sigma^{\iota}$ & CREDIT, $c_{t i}$ & & & \\
\hline 4 & $\begin{array}{l}\text { GOOD } \\
\text { POOR }\end{array}$ & $\begin{array}{l}108.4 \\
112.4\end{array}$ & $\begin{array}{l}116.4 \\
120.4\end{array}$ & $\begin{array}{l}126.1 \\
130.1\end{array}$ \\
\hline 5 & $\begin{array}{l}\text { GOOD } \\
\text { POOR }\end{array}$ & $\begin{array}{l}126.1 \\
132.3\end{array}$ & $\begin{array}{l}136.2 \\
140.1\end{array}$ & $\begin{array}{l}144.1 \\
148.0\end{array}$ \\
\hline 6 & $\begin{array}{l}\text { GOOD } \\
\text { POOR }\end{array}$ & $\begin{array}{l}146.2 \\
151.8\end{array}$ & $\begin{array}{l}154.0 \\
159.6\end{array}$ & $\begin{array}{l}163.5 \\
167.3\end{array}$ \\
\hline 7 & $\begin{array}{l}\text { GOOD } \\
\text { POOR }\end{array}$ & $\begin{array}{l}167.3 \\
173.3\end{array}$ & $\begin{array}{l}175.0 \\
182.6\end{array}$ & $\begin{array}{l}184.7 \\
190.2\end{array}$ \\
\hline 8 & $\begin{array}{l}\text { GOOD } \\
\text { POOR }\end{array}$ & $\begin{array}{l}199.8 \\
207.3 \\
\end{array}$ & $\begin{array}{l}207.6 \\
214.7\end{array}$ & $\begin{array}{l}215.1 \\
222.1 \\
\end{array}$ \\
\hline \multicolumn{5}{|l|}{20 YEARS } \\
\hline 4 & $\begin{array}{l}\text { GOOD } \\
\text { POOR }\end{array}$ & $\begin{array}{l}88.0 \\
92.6\end{array}$ & $\begin{array}{l}97.2 \\
101.8\end{array}$ & $\begin{array}{l}106.5 \\
110.9\end{array}$ \\
\hline 5 & $\begin{array}{l}\text { GOOD } \\
\text { POOR }\end{array}$ & $\begin{array}{l}108.0 \\
112.4\end{array}$ & $\begin{array}{l}117.1 \\
121.4\end{array}$ & $\begin{array}{l}126.1 \\
130.7\end{array}$ \\
\hline 6 & $\begin{array}{l}\text { GOOD } \\
\text { POOR }\end{array}$ & $\begin{array}{l}127.5 \\
132.0\end{array}$ & $\begin{array}{l}134.9 \\
141.0\end{array}$ & $\begin{array}{l}143.7 \\
149.7\end{array}$ \\
\hline 7 & $\begin{array}{l}\text { GOOD } \\
\text { POOR }\end{array}$ & $\begin{array}{l}148.3 \\
153.9\end{array}$ & $\begin{array}{l}155.5 \\
161.1\end{array}$ & $\begin{array}{l}164.1 \\
170.0\end{array}$ \\
\hline 8 & $\begin{array}{l}\text { GOOD } \\
\text { POOR }\end{array}$ & $\begin{array}{l}177.0 \\
184.0\end{array}$ & $\begin{array}{l}184.3 \\
191.0\end{array}$ & $\begin{array}{l}193.4 \\
199.3\end{array}$ \\
\hline \multicolumn{5}{|l|}{30 YEARS } \\
\hline 4 & $\begin{array}{l}\text { GOOD } \\
\text { POOR }\end{array}$ & $\begin{array}{l}77.6 \\
81.0\end{array}$ & $\begin{array}{l}87.9 \\
91.4\end{array}$ & $\begin{array}{l}97.0 \\
101.4\end{array}$ \\
\hline 5 & $\begin{array}{l}\text { GOOD } \\
\text { POOR }\end{array}$ & $\begin{array}{l}97.1 \\
102.6\end{array}$ & $\begin{array}{l}107.0 \\
111.5\end{array}$ & $\begin{array}{l}117.0 \\
121.3\end{array}$ \\
\hline 6 & $\begin{array}{l}\text { GOOD } \\
\text { POOR }\end{array}$ & $\begin{array}{l}114.7 \\
120.1\end{array}$ & $\begin{array}{l}124.6 \\
129.9\end{array}$ & $\begin{array}{l}134.2 \\
139.6\end{array}$ \\
\hline 7 & $\begin{array}{l}\text { GOOD } \\
\text { POOR }\end{array}$ & $\begin{array}{l}133.2 \\
138.6\end{array}$ & $\begin{array}{l}141.6 \\
148.0\end{array}$ & $\begin{array}{l}151.1 \\
156.3\end{array}$ \\
\hline 8 & $\begin{array}{l}\text { GOOD } \\
\text { POOR }\end{array}$ & $\begin{array}{l}154.2 \\
162.6\end{array}$ & $\begin{array}{l}162.8 \\
169.7\end{array}$ & $\begin{array}{l}169.9 \\
176.8\end{array}$ \\
\hline
\end{tabular}

NOTES: The original mortgage rate is set equal to 10 percent, the average coupon rate of the sample. $\ell_{t i}$ represents the current loan-to-value ratio (percent); $c_{t i}$ is the worst delinquency ever $(\mathrm{GOOD}=$ unblemished credit, $\mathrm{POOR}=$ homeowner has defaulted $) ; \sigma^{\iota}$ represents the implied price volatility on options on the 10-year treasury note futures (basis points). 